\title{
Mesoporous Structured Silica - An improved catalyst for direct amide synthesis and its application to continuous flow processing
}

\author{
James W. Comerford, Thomas J. Farmer, Duncan J. Macquarrie, * Simon W. Breeden, \\ and James H. Clark
}

\author{
Green Chemistry Centre of Excellence, Department of Chemistry, University of York, \\ Heslington, York, YO10 5DD, UK \\ E-mail: Duncan.Macquarrie@york.ac.uk
}

This paper is dedicated to Professor Keith Smith, for the occasion of his 65th birthday

\begin{abstract}
We recently published details of an effective, reusable and benign heterogeneous amidation catalyst based on thermal treatment of amorphous K60 silica, however the loading of catalyst required was high for some reactions. We report herein our further development of a series of heterogeneous catalysts based on structured silica (SBA) that retain all the green credentials of the previously described amorphous silica, but with increased efficiency. These catalysts were then utilised in continuous flow systems, achieving excellent conversions with dramatically reduced reaction times.
\end{abstract}

Keywords: SBA-15, silica, amide, continuous process

\section{Introduction}

The formation of amides is one of the most important reactions in the pharmaceutical industry, though typically suffers from poor atom economy, with stoichiometric activating agents being required to achieve amide formation. ${ }^{1}$ In addition, many bio-derived platform molecules are acids, and there is great need to develop clean synthetic routes to form derivatives of these molecules, thus broadening the range of natural and sustainably derived pharmaceutical products. ${ }^{2-4}$ Ishihara and Whiting have both recently published catalytic routes to amides using boronic acids as catalysts, but the syntheses and recovery of these materials were problematic and the E-factor for amide synthesis when including the synthesis of the catalyst, but assuming no recovery, was high. ${ }^{5-6}$ We recently published research on a new route to amides using thermally-treated chromatographic silica as a clean and reusable catalyst, giving excellent yields (>70\%) for a range of amides. ${ }^{7}$ More recently, Akamanchi et al. have demonstrated that sulfated 
tungstate is also an effective catalyst for this reaction. ${ }^{8}$ While both of these systems have clear benefits over existing routes, both require significant amounts of catalyst (typically $20 \%$ wt silica, and $18 \%$ wt sulfated tungstate). ${ }^{7-8}$ Additionally, it was deemed desirable to develop a continuous process for the synthesis of amides, as the selectivity to product is excellent and therefore recycling of the unreacted fraction would be very advantageous. Other benefits associated with the use of continuous flow processing include improved safety due to smaller quantity of solvent/reaction mixture being heated at any one time as well as control of reagent concentration, higher catalyst to reagent ratio, and easier scale-up. ${ }^{1-3}$

We present our results for amide synthesis with mesoporous structured silicas (SBA-15), which have very well defined, regular, linear pores, which allow for excellent diffusion. While the reaction rates were broadly comparable to those using chromatographic silica, significantly less catalyst was required, and the catalysts were reusable and successfully applied in a flow reactor, with easy recycling of unreacted starting material.

\section{Results and Discussion}

The preparation of the SBA catalysts was carried out according to literature procedures. ${ }^{9}$ Three catalysts were prepared, the first using Pluronic P123 as the template (SBA-15), the second using Pluronic P123 as a template and 1,3,5-trimethylbenzene (TMB) as a template expander (SBA15TMB), and the third using Pluronic P123 as a template and 1,3,5-triisopropylbenzene (TPB) as a template expander (SBA-15TPB), to give analogous catalysts with increasing pore diameters. In order to remove the template and activate the materials for catalysis, they were calcined under air at a series of temperatures from $500{ }^{\circ} \mathrm{C}$ to $900{ }^{\circ} \mathrm{C}$. The textural properties of the resultant materials are shown in Table 1 . As can be seen, the pore diameter increases, as expected, from SBA-15 to SBA-15TMB to SBA-15TPB. In each case, the surface area and pore volume fell steadily over the range of activation temperatures. This was accompanied by a rise in average pore diameter as the materials crosslink density increased. However, it can be inferred from the regularity of the trends that no substantial reorganisation or collapse of the materials took place, consistent with the reported stability of the materials up to $1100{ }^{\circ} \mathrm{C}^{10}$

In contrast, the $\mathrm{K} 60$ silica changed little up to $700{ }^{\circ} \mathrm{C}$ (data at $300{ }^{\circ} \mathrm{C}$ activation are within experimental error of those at $500{ }^{\circ} \mathrm{C}$ ). From $700{ }^{\circ} \mathrm{C}$ there was a dramatic drop in surface area and average pore volume, as the material underwent a phase change and partial collapse, thus causing the erratic pore diameter data. In comparison with K60 at temperatures at and below 700 ${ }^{\circ} \mathrm{C}$, the SBA materials have somewhat higher surface area and generally similar or higher average pore volumes. Pore diameter was harder to assess due to the different morphology of the pores of K60 and SBAs, though it was likely that rates of diffusion within the relatively linear and regular SBA materials were faster than those within the irregular tortuous pores of amorphous K60. The structured channels (circled, Figure 1) are clearly visible in the transmission electron microscopy (TEM) image of SBA-15, showing the material to have an 
estimated pore width of $4 \mathrm{~nm}$, correlating with porosimetry data. The larger SBAs exhibited identical characteristics, and no interconnecting pores were observed. This, together with other investigative techniques, suggest that, from this porosimetry and TEM data, the synthesis of structured silica with an ordered porous network was successful.

Table 1. Textural properties of catalysts prepared, along with K60 silica for comparison. Note: pore diameters for the SBA materials had a narrow distribution and were approximately linear, those of K60 were amorphous, with a wide range of pore sizes and shapes

\begin{tabular}{lcccc}
\hline \multicolumn{1}{c}{ Material } & $\begin{array}{c}\text { Activation } \\
\text { temperature }\left({ }^{\circ} \mathrm{C}\right)\end{array}$ & $\begin{array}{c}\text { BET surface } \\
\text { area }\left(\mathrm{m}^{2} \mathrm{~g}^{-1}\right)\end{array}$ & $\begin{array}{c}\text { Total pore volume } \\
\left(\mathrm{cm}^{3} \mathrm{~g}^{-1}\right)\end{array}$ & $\begin{array}{c}\text { Average pore } \\
\text { diameter }(\mathrm{nm})\end{array}$ \\
\hline SBA-15 & 500 & 730 & 0.72 & 4.0 \\
SBA-15 & 600 & 660 & 0.66 & 4.2 \\
SBA-15 & 700 & 600 & 0.59 & 4.5 \\
SBA-15 & 800 & 535 & 0.53 & 4.7 \\
SBA-15 & 900 & 470 & 0.46 & 5.0 \\
SBA-15TMB & 500 & 650 & 0.76 & 7.5 \\
SBA-15TMB & 600 & 600 & 0.71 & 7.8 \\
SBA-15TMB & 700 & 550 & 0.65 & 7.9 \\
SBA-15TMB & 800 & 480 & 0.58 & 8.2 \\
SBA-15TMB & 900 & 400 & 0.50 & 8.4 \\
SBA-15TPB & 500 & 590 & 0.81 & 10.8 \\
SBA-15TPB & 600 & 550 & 0.76 & 10.8 \\
SBA-15TPB & 700 & 510 & 0.70 & 13.5 \\
SBA-15TPB & 800 & 440 & 0.64 & 16.3 \\
SBA-15TPB & 900 & 345 & 0.53 & 5.7 \\
K60 silica & 500 & 470 & 0.68 & 5.7 \\
K60 silica & 600 & 455 & 0.65 & 6.5 \\
K60 silica & 700 & 330 & 0.54 & 7.4 \\
K60 silica & 800 & 195 & 0.36 & 6.3 \\
K60 silica & 900 & 110 & 0.18 & \\
\hline
\end{tabular}

$\mathrm{XRF}$ analysis was undertaken on each of the structured silicas to ensure high purity and absence of metal contamination. The composition of each of SBA was identical and showed high silica percentage (99.6\%), with trace quantities of $\mathrm{PdO}(0.2 \%)$ and $\mathrm{SnO}_{2}(0.18 \%)$. No aluminium or iron contaminant was observed. 


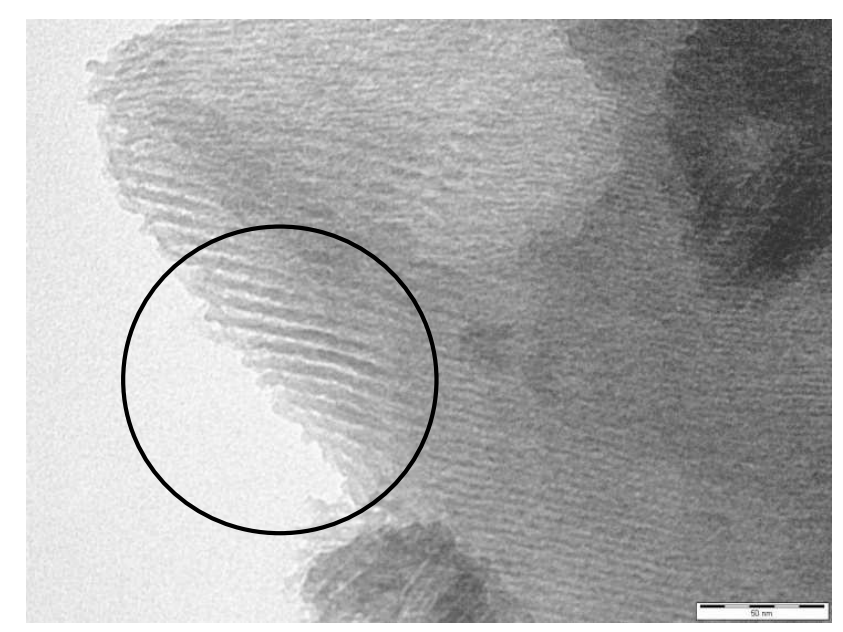

Figure 1. TEM image of SBA-15 - full scale bar is $50 \mathrm{~nm}$.

\section{Amide formation}

A range of acids (phenylacetic acid 1, 2-phenylpropanoic acid 2, 4-chlorophenoxyacetic acid 3 and propanoic acid 4) and amines (aniline 5, 2-chloroaniline 6, 3-aminopropan-1-ol 7, 4hydroxyaniline 8 and 4-methoxyaniline 9) were reacted together in a 1:1 molar ratio in refluxing toluene. Reactions were followed by gas chromatography, and product isolated after 24 hours, at which time no further conversion was observed. The results are given in Table 2 for SBA-15TPB and $\mathrm{K} 60$, both activated at $700{ }^{\circ} \mathrm{C}$.

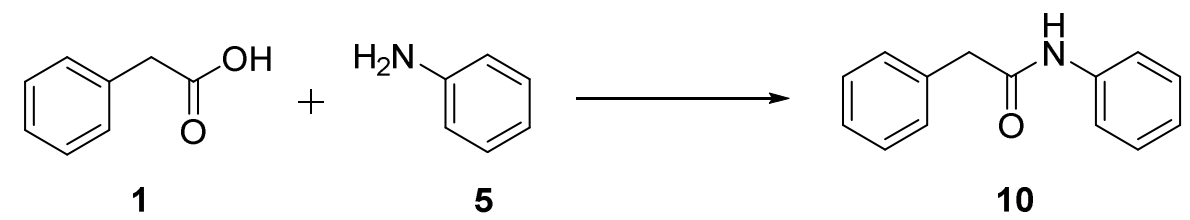

Scheme 1. Reaction of phenylacetic acid (1) with aniline (5) to form $N$-(phenyl)phenylacetamide (10).<smiles>O=C(O)Cc1ccccc1</smiles>

1<smiles>CC(C(=O)O)c1ccccc1</smiles>

2<smiles>O=C(O)COc1ccc(Cl)cc1</smiles>

3<smiles>CCC(=O)O</smiles>

4

Figure 2. Carboxylic acids used in the screen of catalyst activity for amide formation. 


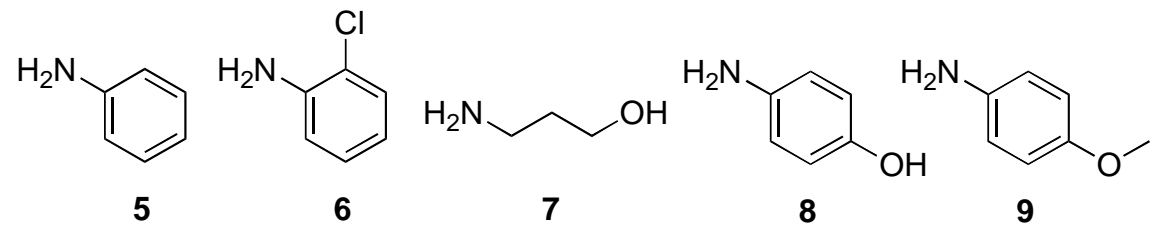

Figure 3. Amines used in the screen of catalyst activity for amide formation.

A comparison was made between $20 \%$ wt $\mathrm{K} 60$ (with respect to mass of reactants) and $5 \% \mathrm{wt}$ SBA-15TPB, as these represented the optimum loading of each catalyst. 5\%wt loading of K60 gave poor results (e.g. $\sim 24 \%$ conversion for phenylacetic acid with aniline). Blank reactions (no catalyst) were carried out for all the above amine and carboxylic acid combinations, with <5\% yields observed in each case, except Entry 1, where $10 \%$ product was obtained. In each case SBA catalyst performed as well at $5 \% \mathrm{wt}$ as the $\mathrm{K} 60 \mathrm{did}$ at $20 \% \mathrm{wt}$, with increased quantities of either catalyst bringing little additional yield. Reducing the quantities of catalyst reduced yield in all cases.

Table 2. Yield of reactions between carboxylic acids and amines

\begin{tabular}{ccccc}
\hline Entry & Carboxylic Acid & Amine & \multicolumn{2}{c}{ Yield $^{\mathrm{b}}$} \\
\cline { 4 - 5 } & & & SBA15TPB $^{\mathrm{c}} 5 \mathrm{wt} \%$ & K60 20 $^{2} \%$ \\
\hline 1 & $\mathbf{1}$ & $\mathbf{5}$ & 79 & 81 \\
2 & $\mathbf{2}$ & $\mathbf{5}$ & 55 & 59 \\
3 & $\mathbf{3}$ & $\mathbf{5}$ & 84 & 73 \\
4 & $\mathbf{4}$ & $\mathbf{5}$ & 64 & 72 \\
5 & $\mathbf{1}$ & $\mathbf{6}$ & 39 & 48 \\
6 & $\mathbf{1}$ & $\mathbf{7}$ & $49(6 \%)^{\mathrm{f}}$ & $36(10 \%)^{\mathrm{f}}$ \\
7 & $\mathbf{1}$ & $\mathbf{7}$ & $52^{\mathrm{d}}(2 \%)^{\mathrm{f}}$ & - \\
8 & $\mathbf{1}$ & $\mathbf{7}$ & $59^{\mathrm{e}}(28 \%)^{\mathrm{f}}$ & - \\
9 & $\mathbf{1}$ & $\mathbf{8}$ & 49 & 50 \\
10 & $\mathbf{1}$ & $\mathbf{9}$ & 96 & 98 \\
\hline
\end{tabular}

(a) $12 \mathrm{mmol}$ of each reagent in toluene at $0.6 \mathrm{M}$ initial concentration of acid and amine. (b) yield after 24 hours, (c) 5\%wt SBA-15TPB activated at $700{ }^{\circ} \mathrm{C}$, (d) 5\%wt SBA-15TMB activated at $700{ }^{\circ} \mathrm{C}$, (e) $5 \%$ wt SBA-15 activated at $700{ }^{\circ} \mathrm{C}$, (f) yield in brackets is percentage of ester.

Entries 6-8 indicate that, for these substrates, there was an inversion in the usual activity of the catalysts, with the smaller pore SBA-15 being the most active and the largest pore SBA15TPB being the least active. SBA-15 was also significantly more selective compared to K60 in terms of amide formation versus undesired esterification, with an amide/ester ratio of 29.5 and 3.6 respectively. This was likely related to the varied surface polarity of the catalysts, whereby increased polarity of the smaller pore SBA-15 allows reduced conversion to ester by-product, 
thereby increasing overall amide conversion. It is possible that this may be related to interaction between the ester group and silanols present on the silica surface, although we have no evidence supporting this.

The influence of activation temperature was broadly similar to that reported for the K60 catalyst, with $700{ }^{\circ} \mathrm{C}$ being the optimum activation temperature for both SBA-15TMB and SBA15TPB. SBA-15 itself showed little variation in performance over the activation range 500-900 ${ }^{\circ} \mathrm{C}$. In all cases with SBA catalysts there was a less pronounced drop in activity at the high end of the temperature range, due to the higher thermal stability of the material compared to K60, which had largely collapsed by $900{ }^{\circ} \mathrm{C}$.

\section{Catalyst reuse}

With a view to continuous processing, fresh reagents were added to a reaction mixture after a 24 hour reaction, and the reaction continued for a further 24 hours. The ability of the catalyst to retain activity was measured by comparing the ratio of the percentage conversion in the 24 hours after the second addition $\left(\%_{\mathrm{b}}\right)$ to the percentage conversion with the first batch of reactants $\left(\%_{\mathrm{a}}\right)$. For the four catalysts studied $\%_{\mathrm{b}} / \%_{\mathrm{a}}$ was as follows: activated K60 0.48; SBA-15 0.43; SBA15TMB 0.76 and SBA-15TPB 0.96. It is evident that the largest pore SBA had not only the highest rate of reaction, but also retained this on reuse.

\section{Application to a continuous flow reactor}

An Uniqsis Flow Syn flow reactor with a $6.6 \mathrm{~mm}$ i.d. x $100 \mathrm{~mm}$ length column was used for this work (Figure 4). The column was packed with the desired catalyst and a premixed phenylacetic acid (1) and aniline (5) mixture (each 0.6 M in toluene) was initially preheated to $150{ }^{\circ} \mathrm{C}$ and then pumped through the column, also kept at $150{ }^{\circ} \mathrm{C}$, using a back pressure regulator. Fractions were collected and analysed by gas chromatography. Operating conditions were optimised using K60 catalyst.

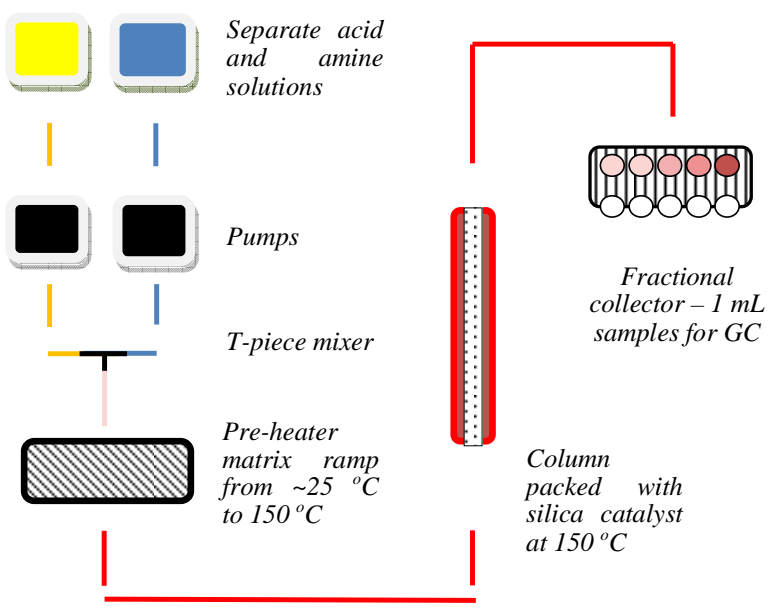

Figure 4. Schematic of continuous flow process. 
Temperatures lower than $150{ }^{\circ} \mathrm{C}$ led to lower conversions, above $150{ }^{\circ} \mathrm{C}$ caused overpressurisation of the system. Under these conditions, conversion was $3 \%$ without catalyst and $17 \%$ with $1 \mathrm{~g}$ activated $\mathrm{K} 60$ catalyst on a one pass basis.

Rate of flow through the catalyst bed was investigated showing an inverse relationship between flow rate and conversion (Table 3 )

Table 3. Relationship between flow rate and conversion using activated K60 catalyst packed continuous flow reactor

\begin{tabular}{ccccc}
\hline $\begin{array}{c}\text { Catalyst } \\
\text { quantity }(\mathrm{g})\end{array}$ & $\begin{array}{c}\text { Flow rate } \\
\left(\mathrm{mL} \mathrm{min}^{-1}\right)^{\mathrm{a}}\end{array}$ & $\begin{array}{c}\text { Residence time } \\
(\text { minutes })^{\mathrm{b}}\end{array}$ & $\begin{array}{c}\text { Conversion to } \\
\text { product }^{\mathrm{c}}\end{array}$ & $\begin{array}{c}\text { Output } \\
\left(\mathrm{g} \mathrm{h}^{-1}\right)^{\mathrm{d}}\end{array}$ \\
\hline 1 & 0.1 & 23.3 & $46 \%$ & 0.349 \\
1 & 0.2 & 11.6 & $25 \%$ & 0.380 \\
1 & 0.3 & 7.8 & $17 \%$ & 0.388 \\
1 & 0.4 & 5.8 & $12 \%$ & 0.365 \\
1 & 0.5 & 4.7 & $9 \%$ & 0.342 \\
\hline
\end{tabular}

(a) Total flow rate from mixer, where the pumps share the flow rate in a 1:1 ratio, (b) Calculated from volume of catalyst and flow rate, (c) Continual conversion after 1 hour stabilisation, (d) output calculated as mass, $\mathrm{g}$, of product produced per hour.

While percentage conversion decreased substantially with decreasing residence time, there was a smaller effect on output as measured by mass of product per unit time, with an optimum $\left(0.388 \mathrm{~g} \mathrm{~h}^{-1}\right)$ being observed at an intermediate flow rate $\left(0.3 \mathrm{~mL} \mathrm{~min}^{-1}\right)$. Using the optimum 0.3 $\mathrm{mL} \min ^{-1}$ flow rate, the effect of catalyst quantity was investigated. A linear relationship was found between catalyst quantity and conversion or output. The column had a maximum capacity of $3 \mathrm{~g} \mathrm{K60}$; at this quantity conversion was $49 \%$, and output $1.12 \mathrm{~g} \mathrm{~h}^{-1}$. Runs were up to 5 hours in duration, with conversion and output steady throughout this time, and no tail off from catalyst deactivation observed.

The SBA catalysts had significantly lower bulk densities than activated K60, and consequently it was not possible to use more than $0.8 \mathrm{~g}$ of catalyst in the column. As seen from Table 4 there was a distinct increase in catalytic activity from SBA-15 to larger pore variants, with SBA-15TPB being capable of effecting almost as much conversion as K60 despite the significant drop in amount of catalyst present ( $0.8 \mathrm{~g}$ and $3 \mathrm{~g}$ respectively). For comparison, $1 \mathrm{~g}$ of activated K60 effected a $17 \%$ conversion, and conversion was found to vary linearly with catalyst mass.

A range of substrate pairs was tested using activated K60 catalyst under flow conditions. The results are shown in Table 5, where $\mathbf{1 1}$ is 2-methoxyethylamine, $\mathbf{1 2}$ is 3-methoxyaniline and $\mathbf{1 3}$ is pyrrolidine (Figure 5). In each case conversion was substantially higher in the flow reactor than in a batch. The flow rate of the continuous reactor was set such that after one hour $20 \mathrm{~mL}$ of reagent and solvent had flowed through the reactor, the same volume as in the batch reactor, 
although the continuous reactor had six times as much catalyst. The conversions reached in the continuous reactor were 4.3 - 10 times higher than in the initial hour of the batch. Two factors should be borne in mind. Firstly, the rate of reaction in the batch process was highest during the first hour - the average hourly rate of conversion after the 24 hours needed to complete the reactions in batch mode was significantly lower (e.g. for the first example, this can be calculated to be $0.08 \mathrm{~g} \mathrm{~h}^{-1}$ ). ${ }^{7}$ Secondly, the effect of increasing catalyst quantity in the batch reaction (so that is approaches that of the continuous system) was minimal. Little or no benefit in conversion or rate of reaction was seen, and both systems were operating at their optimum. Therefore the major reason for increased productivity was a combination of the increased temperature possible in the continuous reactor and the continual removal of product and replenishment of starting materials in the flow system.

Table 4. Comparison of catalyst types

\begin{tabular}{ccccc}
\hline $\begin{array}{c}\text { Catalyst quantity } \\
(\mathrm{g})\end{array}$ & Catalyst type & $\begin{array}{c}\text { Residence } \\
\text { time } \\
\text { (minutes) }\end{array}$ & $\begin{array}{c}\text { Conversion to } \\
\text { product }^{\mathrm{a}}\end{array}$ & $\begin{array}{c}\text { Output } \\
\left(\mathrm{g} \mathrm{h}^{-1}\right)^{\mathrm{b}}\end{array}$ \\
\hline 0.8 & SBA-15 & 23.3 & $25 \%$ & 0.570 \\
0.8 & SBA-15TMB & 23.3 & $31 \%$ & 0.707 \\
0.8 & SBA-15TPB & 23.3 & $42 \%$ & 0.958 \\
3 & K60 - 700 & 23.3 & $49 \%$ & 1.118 \\
\hline
\end{tabular}

Flow rate $0.3 \mathrm{~mL} \mathrm{~min}{ }^{-1}, 150{ }^{\circ} \mathrm{C}$ column and reagent temperature, (a) continual conversion after 1 hour stabilisation (b) output calculated as mass, $\mathrm{g}$, of product produced per hour.

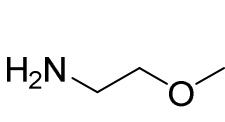

11<smiles>COc1cccc(N)c1</smiles>

12

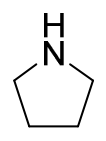

13

Figure 5. Alternative amines used in the screen of catalyst activity of activated K60 for amide formation under continuous flow.

With continual use of the catalyst, deactivation over time becomes a particularly important parameter. The synthesis of $\mathrm{N}$-(phenyl)-phenylacetamide was performed using 3 grams of activated $\mathrm{K} 60$, a flow rate of $0.3 \mathrm{~mL} \mathrm{~min}^{-1}$ and a pre-heater and column temperature of $150{ }^{\circ} \mathrm{C}$, sampled over 4 hours. Figure 6 shows that conversion remained consistent over the sample period, evidently showing no sign of catalyst inhibition or poisoning over the time period investigated. This can be attributed to the constant flow of hot solution through the catalyst bed, loading fresh acid onto the catalyst and effectively washing the less polar product off the column. 
Table 5. Reaction screening using continuous flow

\begin{tabular}{cccccc}
\hline \multirow{2}{*}{ Acid } & Amine & \multicolumn{2}{c}{$\begin{array}{c}\text { Continuous flow } \\
\text { conversion }^{\mathrm{a}}\end{array}$} & \multicolumn{2}{c}{$\begin{array}{c}\text { Batch reaction } \\
\text { conversion }^{\mathrm{a}}\end{array}$} \\
\cline { 3 - 6 } & & $(\%)^{\mathrm{b}}$ & $\mathrm{g} \mathrm{hour}^{-1}$ & $(\%)^{\mathrm{c}}$ & $\mathrm{g} \mathrm{hour}^{-1}$ \\
\hline $\mathbf{1}$ & $\mathbf{5}$ & 49 & 1.118 & 7 & 0.127 \\
$\mathbf{1}$ & $\mathbf{7}$ & $33^{\mathrm{d}}, 4^{\mathrm{e}}$ & 0.688 & $3^{\mathrm{d}}$ & 0.069 \\
$\mathbf{1}$ & $\mathbf{1 1}$ & 42 & 0.876 & 8 & 0.185 \\
$\mathbf{1}$ & $\mathbf{1 2}$ & 38 & 0.990 & 4 & 0.116 \\
$\mathbf{1}$ & $\mathbf{1 3}$ & 34 & 0.695 & 7 & 0.159 \\
$\mathbf{4}$ & $\mathbf{5}$ & 42 & 0.677 & 6 & 0.107 \\
\hline
\end{tabular}

(a) A 0.6 M solution was used for continuous flow and batch reaction, where on average the quantity of catalyst used in continuous flow was 6 times more. (b) continuous conversion, (c) conversion in the first hour corresponds to the maximum conversion in a batch system (d) $\mathrm{N}$-(3hydroxypropyl)-phenyl-acetamide, (e) phenylacetic acid 3-aminopropyl ester.

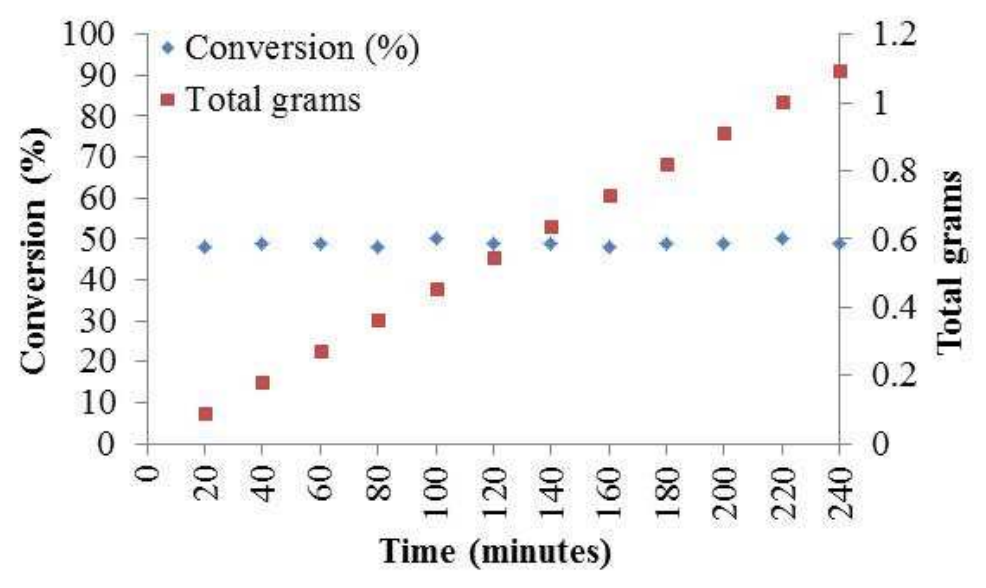

Figure 6. Continual synthesis of $N$-(phenyl)-phenylacetamide.

To explore enhancing yields further a recirculation method was developed. The method relied upon the amide crystallising out of solution in a cooling reservoir, with unreacted acid remaining in solution. This parameter was investigated by placing two separate $20 \mathrm{~mL} 0.6 \mathrm{M}$ solutions of phenylacetic acid and $N$-(phenyl)-phenylacetamide into a jacketed cooling reservoir containing deionised water. The temperature was slowly decreased from room temperature at 0.5 ${ }^{\circ} \mathrm{C}$ intervals aiming to identify at which temperature the acid and amide crystallised from solution. The acid remained in solution down to a temperature of $6{ }^{\circ} \mathrm{C}$, whereas the amide began to crystallise out at $10{ }^{\circ} \mathrm{C}$ with substantial crystallisation $(94 \%)$ at $8{ }^{\circ} \mathrm{C}$, where no acid was observed. The reaction mixture from the column was set to elute at the bottom of the reservoir (replacing the fractional collector in Figure 4), cool and then crystallise, where the unreacted 
solution was taken from the top (to avoid blockage). The method of synthesis was to first circulate all of the reaction mixture through the system and then recirculate the solution though again, without introducing "fresh" reagents. The isolated yields for this method are shown in Table 6.

Table 6. Isolated yields for the synthesis of $N$-(phenyl)-phenylacetamide using the recirculation method

\begin{tabular}{cccc}
\hline $\begin{array}{c}\text { Number of recirculations } \\
(20 \mathrm{~mL})\end{array}$ & $\begin{array}{c}\text { Isolated } \\
\text { yield }^{\mathrm{b}}\end{array}$ & $\begin{array}{c}\text { Total time }^{\mathrm{c}} \\
(\text { mins })\end{array}$ & $\begin{array}{c}\text { Average yield } \\
\mathrm{g} \mathrm{h}^{-1} \mathrm{~d}\end{array}$ \\
\hline 1 & 49 & 67 & 1.11 \\
2 & 68 & 134 & 0.771 \\
3 & 78 & 201 & 0.590 \\
4 & 83 & 268 & 0.470 \\
Batch & 81 & 24 hours & 0.085 \\
\hline
\end{tabular}

a) time taken for total quantity of solution in system (including reservoir) to elute from column at $\left.0.3 \mathrm{~mL} \mathrm{~min}^{-1}, \mathrm{~b}\right)$ collected directly from cooled reservoir, identified by GC/MS and melting point. c) time taken for the total number of recirculations, d) from a 0.6 molar $20 \mathrm{~mL}$ solution.

\section{Conclusions}

The use of SBA-15 type silicas has proved beneficial in the catalytic formation of amides directly from a range of carboxylic acids and amines, with significantly lower catalyst loadings required than for activated chromatographic K60 silica. Catalyst deactivation with time was also significantly lower than that found with the K60, and both activity and retention of activity improving with increasing pore size. For a fixed volume continuous processing method K60 was marginally superior to the optimum SBA-15 system, as its higher density meant more catalyst could be loaded in the reaction column. On a weight by weight basis SBA-15 catalysts were superior to K60 silica, particularly when deactivation was taken into account.

\section{Experimental Section}

General. Silica gel K60 was supplied from Fluka. Non-ionic surfactant Pluronic P123 and silicate source tetraethyl orthosilicate (TEOS) were from Sigma-Aldrich at $98 \%$ and $99 \%$ purity respectively. All carboxylic acids and amines were purchased from Sigma-Aldrich. Solvents were from Fisher Scientific. 


\section{Synthesis of SBA catalysts}

Synthesis of SBA-15. ${ }^{11}$ Pluronic P123 (12 g) was completely dissolved in deionised water (312 g) and conc. $\mathrm{HCl}(60 \mathrm{~mL}, 37 \%)$. This was heated to $35^{\circ} \mathrm{C}$ with stirring and to this TEOS (25.6 g) was added dropwise. The resulting gel was kept at this temperature for 24 hours, collected by filtration and washed four times with deionised water $(200 \mathrm{~mL})$. The gel was dried at room temperature under vacuum ready for activation. The calcination process to remove the Pluronic P123 template was to heat at $2{ }^{\circ} \mathrm{C} \min ^{-1}$ to $500{ }^{\circ} \mathrm{C}$ in air and held at this temperature for 6 hours. This was set to higher activation temperatures for some samples, using the same heating rate.

Synthesis of SBA-15TMB and SBA-15TPB. In order to increase SBA pore size, micelle template expanders were used. The synthesis was similar to SBA-15, except for the addition of an equimolar quantity of 1,3,5-trimethylbenzene (TMB) or 1,3,5-triisopropylbenzene (TPB) to the Pluronic P123 to form a homogeneous mixture before heating. This homogeneous mixture was heated to $100{ }^{\circ} \mathrm{C}$, instead of $35^{\circ} \mathrm{C}$. Template removal was performed as for SBA- 15 .

Typical procedure for batch amidation reaction between phenylacetic acid 1 and aniline 5 example using SBA-15TPB catalyst. A dry three-necked round bottom flask, equipped with Suba seal, a thermometer, condenser and stirrer flea was charged with phenylacetic acid (1.63 g, $12 \mathrm{mmol})$, tetradecane (200 $\mu \mathrm{l}$, internal standard), $0.14 \mathrm{~g} \mathrm{SBA}-15 \mathrm{TPB}(5 \mathrm{wt} \%)$ and toluene (20 $\mathrm{mL})$. Once the reaction reached a steady reflux $\left(110^{\circ} \mathrm{C}\right) 1.12 \mathrm{~g}(12 \mathrm{mmols})$ of aniline was added. After 24 hours the reaction mixture was cooled to room temperature, the catalyst removed by filtration, and the toluene removed under reduced pressure to give an off white solid. The crude product was dissolved in a minimum quantity of ethyl acetate and precipitated with cold hexane. The pure amide crystals were isolated via filtration and washed with ice-cold hexane to yield $\mathrm{N}$ (phenyl)-phenylacetamide, $2.00 \mathrm{~g}$ (9.48 mmol, 79\%). Literature m.p. $118{ }^{\circ} \mathrm{C}$; m.p. $118-119{ }^{\circ} \mathrm{C}$; ${ }^{1} \mathrm{H}$ NMR $\left(270 \mathrm{MHz}, \mathrm{CDCl}_{3}\right): \delta=7.25-7.39$ (m, 10H; Ar), 3.49 (s, 2H); ${ }^{13} \mathrm{C} \mathrm{NMR}(270 \mathrm{MHz}$, $\left.\mathrm{CDCl}_{3}\right): \delta=169.12,137.85,134.41,129.47,129.16,128.89,127.61,124.41,119.81,44.76$; IR: $v 3254(\mathrm{NH}), 1655 \mathrm{~cm}^{-1}(\mathrm{C}=\mathrm{O}) .{ }^{12}$ Analytical data for other amides synthesized in this work (Table 2) can be found within the supplementary information.

Typical procedure for flow amidation reaction between phenylacetic acid 1 and aniline 5 example using SBA -15TPB catalyst. An Uniqsis Flow Syn flow reactor with a $6.6 \mathrm{~mm}$ i.d. $x$ $100 \mathrm{~mm}$ length column packed with $0.8 \mathrm{~g}$ of SBA-15TPB catalyst. A premixed phenylacetic acid $(1.63 \mathrm{~g}, 12 \mathrm{mmol})$ and aniline $(1.12 \mathrm{~g}, 12 \mathrm{mmol})$ mixture in $20 \mathrm{~mL}$ of toluene $(0.6 \mathrm{M}$ of each reagent) was preheated to $150{ }^{\circ} \mathrm{C}$ and pumped through the catalyst column $\left(150{ }^{\circ} \mathrm{C}\right)$ at a flow rate of $0.3 \mathrm{~mL} \mathrm{~min}^{-1}$, using a back pressure regulator, until the entire of the premixed solution had passed through the column once (67 minutes). Toluene was removed under vacuum and the crude amide purified as for the batch protocol (above) yielding $1.06 \mathrm{~g} \mathrm{~N}$-(phenyl)phenylacetamide $(5.04 \mathrm{mmol}, 42 \%)$. Alternatively, fractions were collected and analysed by gas chromatography and continuous yields calculated by GC analysis of each fraction and total yields confirmed by isolation. 


\section{References}

1 Constable, D. J.; Dunn, P. J.; Hayler, J. D.; Humphrey, G. R.; Lezner, J. L.; Lindermann, R. J.; Lorenz, K.; Manley, J.; Pearlman, B. A.; Wells, A.; Zaks, A.; Zhang, T. Y. Green Chem. 2007, 9, 411

2 Werpy, T.; Pedersen, G., Top Value Added Chemicals from Biomass, US DOE Report, 2005.

3 (a) Budarin, V. L.; Clark, J. H.; Luque, R.; Macquarrie, D. J. Chem. Commun. 2007, 634. (b) Budarin, V. L.; Clark, J. H.; Luque, R.; Macquarrie, D. J. Chem. Eur. J. 2007, 13, 6914. (c) Budarin, V. L.; Clark, J. H.; Luque, R.; Macquarrie, D. J.; Koutinas, A.; Webb, C. Green Chem. 2007, 9, 992.

4 Delhomme, C.; Weuster-Botz, D.; Kuhn, F. E. Green Chem. 2009, 11, 13.

5 (a) Ishihara, K.; Ohara, S.; Yamamoto, H. J. Org. Chem. 1996, 61, 4196; (b) Ishihara, K.; Ohara, S.; Yamamoto, H. Macromolecules 2000, 33, 3511; (c) Ishihara, K.; Ohara, S.; Yamamoto, H. Org. Synth., Coll. Vol. 2004, 10, 80; (d) Ishihara, K.; Ohara, S.; Yamamoto, H. Org. Synth., Coll.Vol. 2002, 79, 176; (e) Maki, T.; Ishihara, K.; Yamamoto, H. Org. Lett. 2006, 8, 1431.

6 (a) Arnold, K.; Batsanov, A. S.; Davies, B.; Whiting, A. Green Chem. 2008, 10, 124. (b) Charville, H.; Jackson, D.; Hodges, G.; Whiting, A. Chem. Commun. 2010, 1813.

7 Comerford, J. W.; Clark, J. H.; Macquarrie, D. J.; Breeden, S. W. Chem. Commun. 2009, 2562.

8 Chaudhari, P. S.; Salim, S. D.; Sawant, R. V.; Akamanchi, K. G. Green Chem. 2010, 12, 1707.

9 (a) Wang, Y.; Noguchi, M.; Takahashi, Y.; Ohtsuka, Y. Catal. Today 2001, 68, 3. (b) Phuon, T.; Nguyen, B.; Le, J. W.; Shim, W. G.; Moon, H. Microp. Mesop. Mater. 2008, 110, 560.

10 Wang, J.; Liu, Q. Microp. Mesop. Mater. 2005, 83, 225.

11 Wang, Y.; Noguchi, M.; Takahashi, Y.; Ohtsuka, Y. Catalysis Today 2001, 68, 3. (b) Nguyen, T. P. B.; Lee, J. W.; Shim, W. G.; Moon, H. Microp. Mesop. Mater. 2008, 110, 560.

12 (a) Meyer, R. B.; Hauser, C. R. J. Org. Chem. 1961, 26, 3183. (b) Shi, F.; Li, J.; Li, C.; Jia, X., Tetrahedron Lett. 2010, 51, 6049. 